\title{
Imaging of the hip: a systematic approach to the young adult hip
}

\author{
Sara Muñoz Chiamil \\ Claudia Astudillo Abarca
}

Radiology Department, Clinica Las Condes, Santiago Chile

Corresponding author:

Sara Muñoz Chiamil

Radiology Department, Clinica Las Condes, Santiago, Chile

E-mail: smunoz@clinicalascondes.cl

\section{Summary}

Background: Great advances in knowledge and understanding of the biomechanics of the hip, both in arthroscopic procedures and imaging techniques, have expanded and improved the diagnosis of pathologies of the young adult hip. The anatomy of the hip joint is complex due to its morphology and orientation. The interpretation of the images requires deep knowledge of the osseous and soft tissue anatomy: muscles, tendons, ligaments, vessels and nerves. There are multiple imaging tools. Diagnostic techniques have different utilities and often are complementary.

Methods: In this article the various diagnostic imaging techniques for evaluation of hip pathologies are discussed, their indications and usefulness, with emphasis on those resolved arthroscopically.

Conclusion: Young adult hip disorders are increasingly diagnosed and treated as arthroscopic procedures improved. Radiology is a fundamental contribution in the diagnostic process. Plain radiography (X-ray) is always the initial examination.

Level of evidence: $V$.

KEY WORDS: femoro-acetabular impingement, hip arthroscopy, hip dysplasia, hip imaging, hip X-ray, MRI.

\section{Introduction}

X-ray is the basic tool for the study of the hip ${ }^{1,2,3}$. The method of choice to assess the bone marrow, acetabular labrum, cartilage and peri-articular soft tissue, is magnetic resonance imaging (MRI).

Ultrasound (US) also has a role in the evaluation of peri-articular soft tissues and detection of joint effusion or synovial thickening, allowing dynamic assessment of the joint. It can also be used as a guide for diagnostic and/or therapeutic procedures. MRI with intraarticular contrast (MR Arthrography) has better performance than conventional MRI for the evaluation of intraarticular pathology, especially of labrum and cartilage. It also can be used to inject a local anesthetic, for example, and perform the "Lidocaine Test", with clinical diagnostic value.

To assess cartilage in MRI, in addition to the morphological information, dGEMRIC T1 and T2 mapping have been used, which provide information about its composition of water and glycosaminoglycans (GAG). Computed tomography (CT), which use ionizing radiation, has greater spatial and contrast resolution than X-ray. It is useful for joint anatomy, bone lesions hidden to X-ray and fractures.

This article submits to the ethical standards of the journal ${ }^{4}$.

\section{Radiographic evaluation}

There are numerous X-ray views to asses nontraumatic hip in adults ${ }^{1}$. The standard study includes Anteroposterior Pelvic view (AP Pelvic view) to evaluate the acetabulum and joint space, which we recommend in standing position because it add information about pelvic slope and acetabular version.

Depending on the clinical suspicion, some additional localized views of the hip can be used. For example, if Femoracetabular Impingement (FAI) is suspected: true axial or cross-table, $45^{\circ}$ Dunn or $90^{\circ}$ Dunn ${ }^{1,5}$.

To assess anterior acetabular coverage: false profile. For joint pathology or avascular necrosis: Lowenstein (frog leg lateral) view, etc.

Pelvis X-ray determines if the hip is normal, borderline or dysplastic, if there are signs of CAM, PINCER impingement or a combination of both, signs of degenerative or inflammatory arthropathy, avascular necrosis, calcifications, tumors, etc.

The first variable to consider in Pelvic X-ray is quality control, related to symmetry, tilt and rotation (Figure 1). If the diagnosis is FAI, the AP Pelvic view should be taken with lumbar lordosis correction to make the signs and measures of the acetabulum reliable ${ }^{6}$ (Figure 2). 


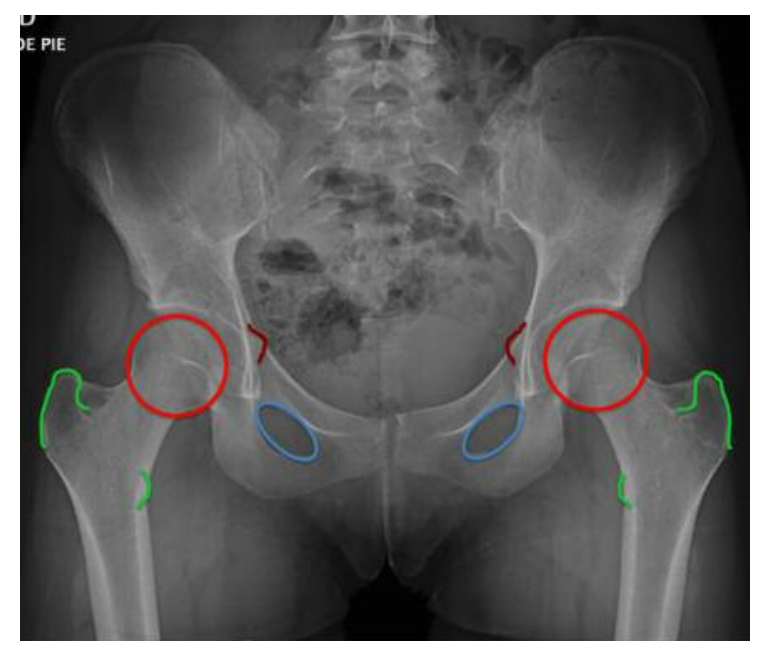

Figure 1. AP pelvic radiograph quality control: symmetric related to femoral heads (red line), obturator foramina (blue line), ischial spines (brown line), greater and lesser trochanter (green line).

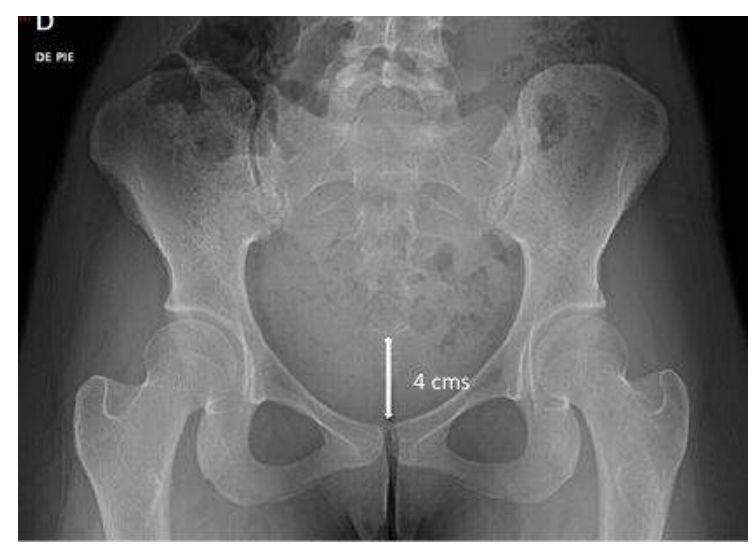

Figure 2. Lordosis correction. Adecuate pelvis inclination: distance between the superior aspect of the pubic symphysis and the sacrococcygeal junction must be approximately $3 \mathrm{cms}$ in men and $4 \mathrm{cms}$ in women.

X-ray analysis must be systematic, beginning with the surrounding soft tissue, where the gluteal, iliopsoas and obturator fat pads should be recognize ${ }^{7}$. These pads define the respective muscles. They must be rectilinear and well defined (Figure 3 ). If they have a convexity implies distension of the hip joint with fluid. The X-ray must be strictly in AP position for this assessment to be valid. Flexion and hip rotation could produce false positives.

\section{Osseous anatomy}

There are landmarks that must be recognized in AP Pelvic view:

a. Iliopectineal or iliopubic line $e^{8,9}$ : formed by the arcuate line of the ilium and the superior border of

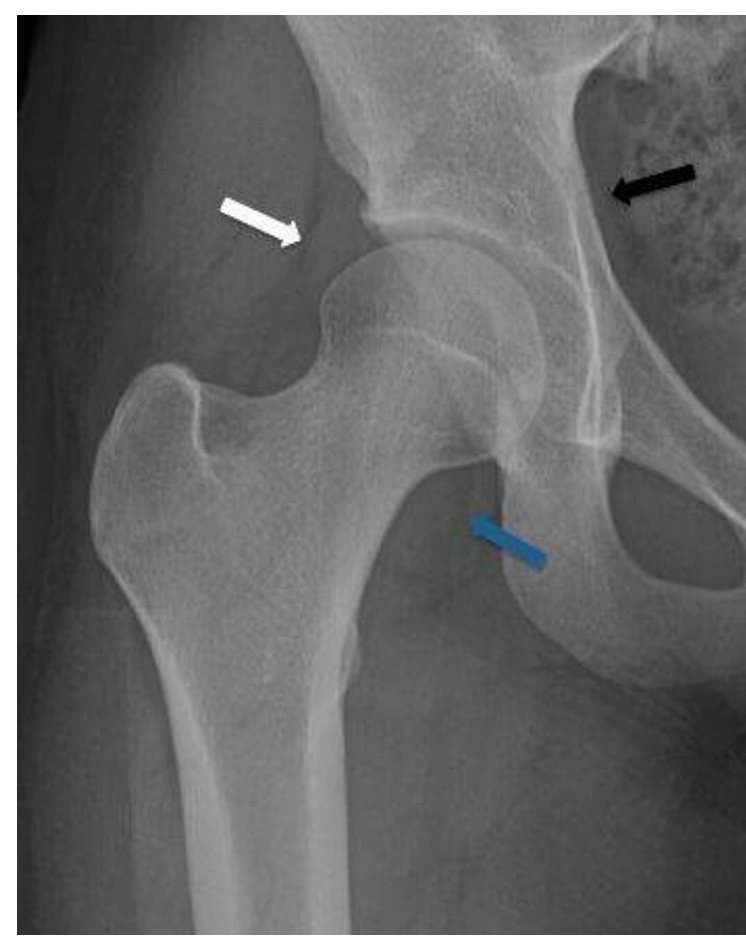

Figure 3. Fat pads of the hip, AP right hip radiograph: Gluteal fat pad (white arrow), Iliopsoas fat pad (blue arrow), Obturator fat pad (black arrow).

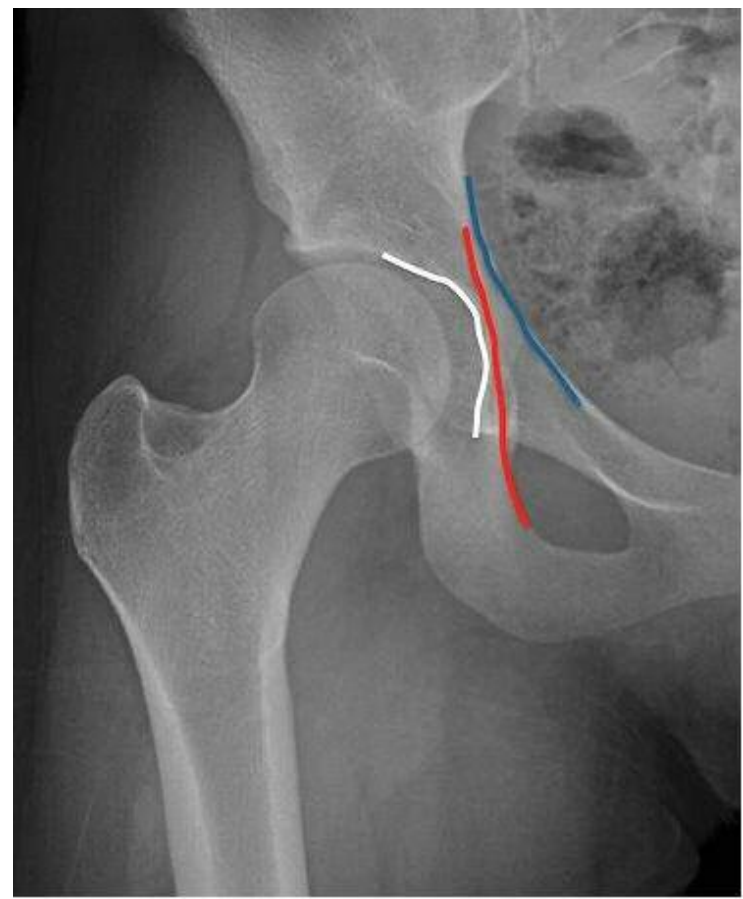

Figure 4. Osseous anatomy: lliopubic line (blue), llioischial line (red), Acetabular floor (white).

the superior pubic ramus. It determines the inner margin of the pelvic ring and it is part of the anterior column of the acetabulum (Figure 4). 

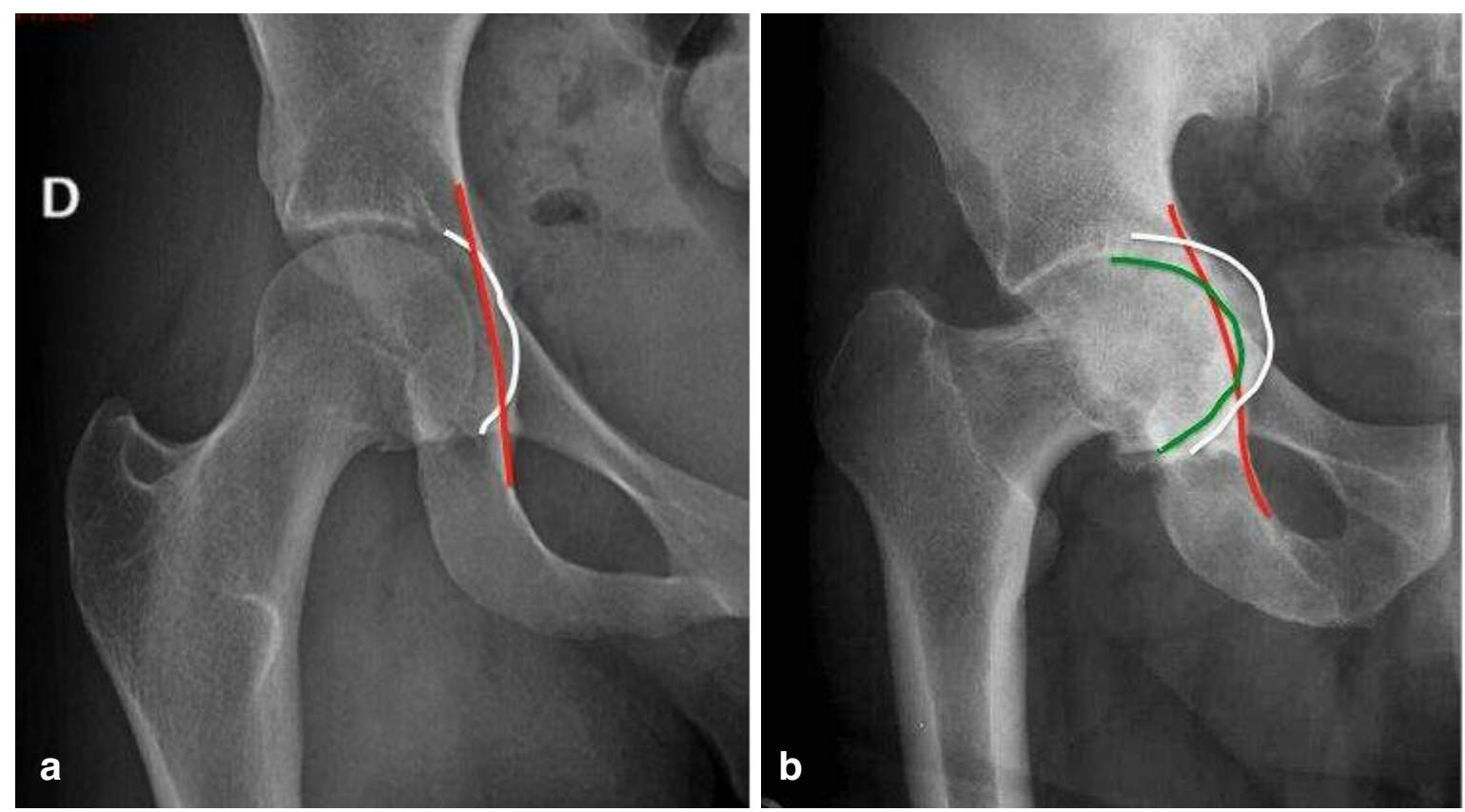

Figure 5 a, b. a) Coxa profunda; b) Acetabular protrusion. Ilioischial line (red), acetabular floor (white), femoral head (green).

b. Ilioischial line: it begins at the medial border of the iliac wing and extends along the medial border of the ischium to end at the ischial tuberosity. It is part of the posterior column of the acetabulum (Figure 4).

c. Acetabular Floor: in normal conditions the floor of the acetabular fossa is lateral to the ilioischial line ( $2 \mathrm{~mm}$ in men, $1 \mathrm{~mm}$ in women). When the acetabular floor overlaps the ilioischial line, coxa profunda is diagnosed (Figure 5 a). Acetabular protrusion is a more severe condition that occurs when the femoral head overlaps or overpasses the ilioischial line ${ }^{6}$ (Figure $5 \mathrm{~b}$ ).

d. Teardrop: it does not correspond to an anatomical structure. It represents a summation of shadows of the medial acetabular wall (Figure 6). It is a useful sign when is asymmetric with the contralateral side. A wider teardrop or greater distance regard to the femoral head can indicate dysplasia or joint effusion ${ }^{7}$.

In normal conditions the femoral acetabular joint space is between 3 and $5 \mathrm{~mm}$ uniformly. To analyze the size of the space is necessary to have an additional axial projection to assess the posterior aspect of the joint that is not shown in the AP Pelvic view (Figure 7 a-d).

\section{Morphology of the acetabulum}

\section{Acetabular coverage}

Normally the acetabulum covers $75 \%$ of the femoral head. Can be determined by three different measurements:

1. Lateral center-edge angle of Wiberg's. In adults

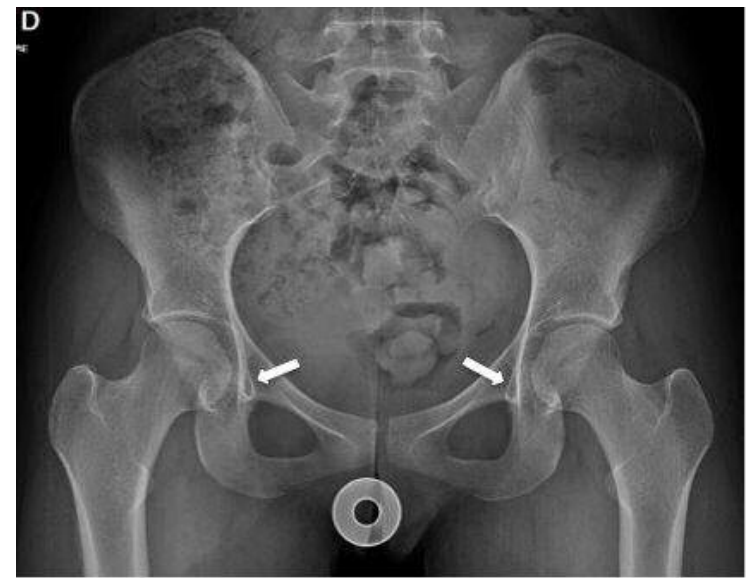

Figure 6. Teardrop (white arrow).

the normal value is $30^{\circ}+/-5^{\circ 1,5,8}$ (Figure 8).

2. Anterior center-edge angle of Lequesne's. Measured in the false profile view. It measures the anterior coverage value $<20^{\circ}$ is considered undercoverage $^{1,8}$ (Figure 9).

3. Femoral head extrusion index. Measures the percentage of the femoral head that is outside of the acetabular roof. This percentage must be $<25 \% 8$ (Figure 10).

\section{Acetubular inclination}

- Sharp's angle: which measures overall acetabular inclination. Angles $>45^{\circ}$ are considered dysplasia $^{8}$ (Figure 11).

- Tönnis angle: measures the inclination of the sclerotic acetabular sourcil (the sclerotic weight- 

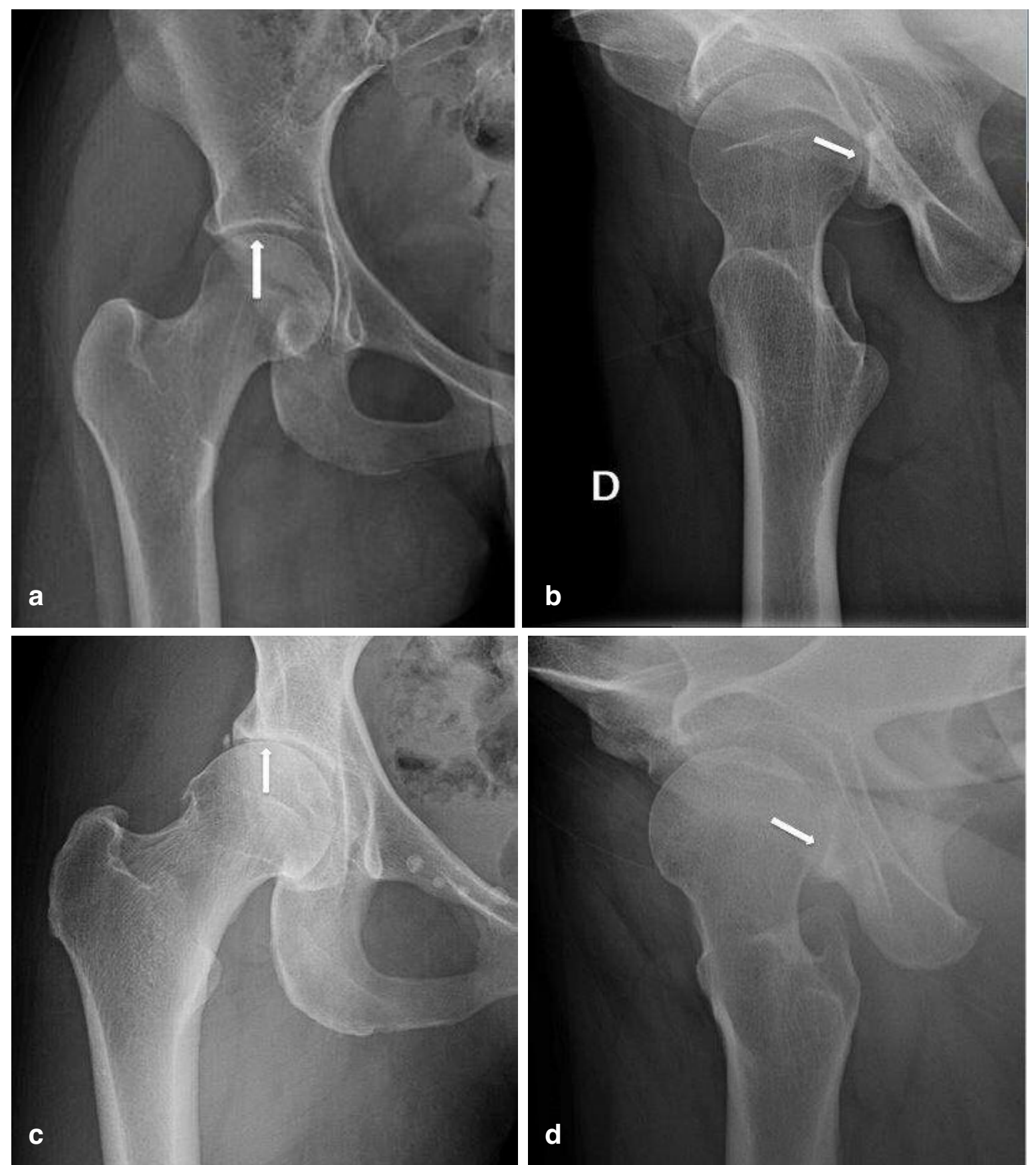

Figure 7 a-d. Femoral acetabular joint space (white arrow): a) AP right hip radiograph with normal superior space; b) true axial or cross-table right hip radiograph with normal posterior space; c) narrow superior space in osteoarthritis; d) narrow posterior space.

bearing portion of the acetabulum) (Figure 12). Values $>10^{\circ}$ are considered in higher risk for instability, $<10^{\circ}$ a risk factor for PINCER impingement ${ }^{1,8}$.

These measurements are important for detection of borderline dysplastic hip ${ }^{9-11}$. This is about young patients, mostly women, who have not been classified as developmental dysplasia in childhood and who show subtle changes in $\mathrm{X}$-ray in early adulthood, with symptoms similar to FAI. They don't have CAM or PINCER radiological signs and can show slightly greater obliquity of the acetabular roof, discrete anterior or lateral undercoverage, subtle loss of sphericity of the femoral head, with or without neck shortening and compensatory hypertrophy of the acetabular labrum, that ossifies and it is detected as a prominent acetabular rim which compensates the femoral coverage (Figure 13 a-c). 


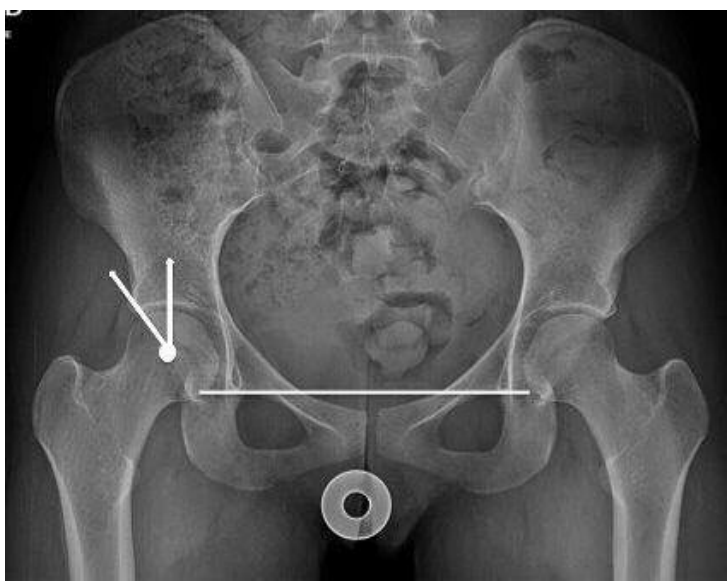

Figure 8. Acetabular coverage. Lateral center-edge angle of Wiberg: AP pelvic view. Angle between a line through the center of the femoral head, perpendicular to the transverse axis of the pelvis, and a second line through the center of the femoral head, passing through the most superolateral point of the sclerotic weight-bearing zone of the acetabulum (acetabular sourcil). Values of $<20^{\circ}$ indicate inadequate lateral coverage of the femoral head.

In MR or MR arthrography, in addition to the anatomical changes described, they may have signs of labral and/or chondral damage similar than FAI. These patients with borderline displastic hips are not candidates for osteotomies or the standard surgical protocols for true hip dysplastia. Most of them are undergoing arthroscopic treatments.

\section{Acetabular version}

Under normal conditions the acetabulum is oriented in anteversion.

The acetabular retroversion is associated with the PINCER type impingement ${ }^{6}$. In X-ray the diagnosis is made with the crossover sign produced when the posterior wall of the acetabulum crosses the anterior wall before reaching the acetabular roof (Figure $14 \mathrm{a}$ ). Other signs associated with acetabular retroversion are: the sciatic spine sign and posterior wall $\operatorname{sig} n^{5,12,13}$. The first is considered positive when the ischial spine projects medial to the iliopectineal line in the AP X-ray of the lumbar spine, indicating that not only the acetabulum, but rather the pelvis, is inclined in retroversion.

The second is considered positive when the posterior wall edge is medial to the femoral head, indicating deficiency of the posterior wall5, 12 (Figure 14 b).

\section{Morphology of the femur}

Under normal conditions the femur has a concave and symmetrical outline at the femoral head-neck junction (femoral offset). When the loss of this bone concavity is produced by a bony protuberance or bump it can cause CAM type impingement $6,12,13$ (Figure $15 \mathrm{a}$ ).

The degree of deformity can be calculated by measuring the alpha angle in the cross table projection or in the $45^{\circ}$ Dunn projection, although the measurement in the MR axial oblique projection is more reliable. It is a measurement of the femoral head

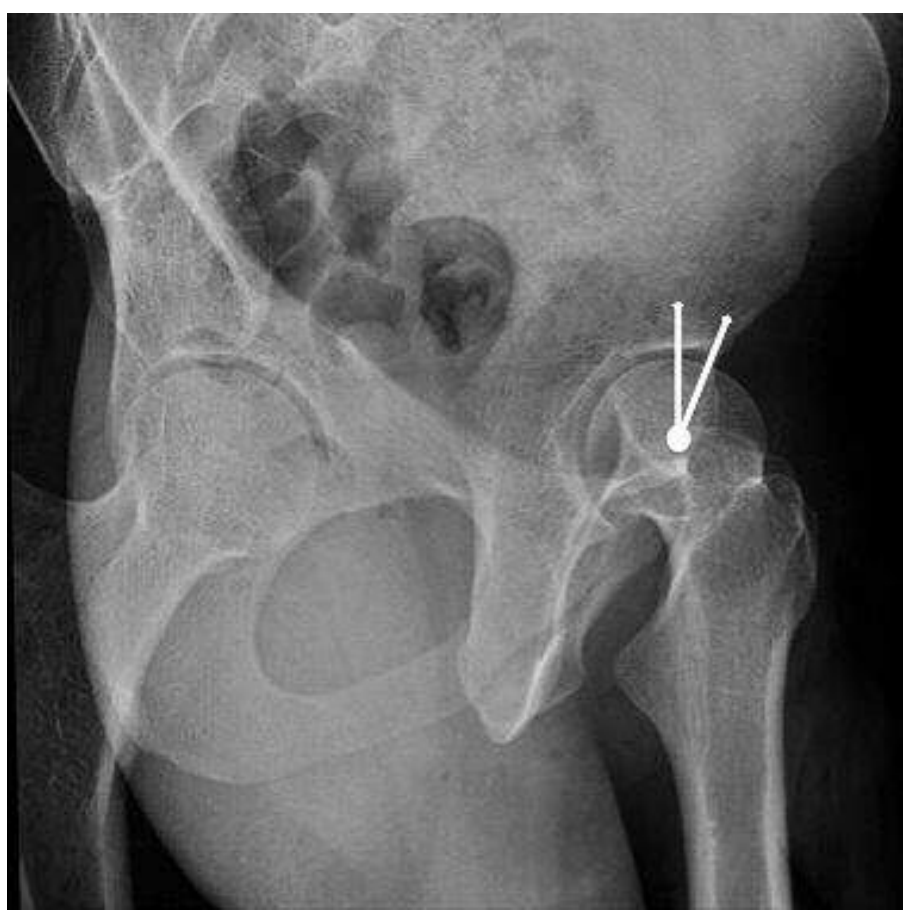

Figure 9. Acetabular coverage. Anterior centeredge angle of Lequesne: False profile view. Angle between a vertical line through the center of the femoral head, and a second line from the center of the femoral head, passing through the most anterior point of the acetabular sourcil. Values of $<20^{\circ}$ indicate inadequate anterior coverage of the femoral head. 


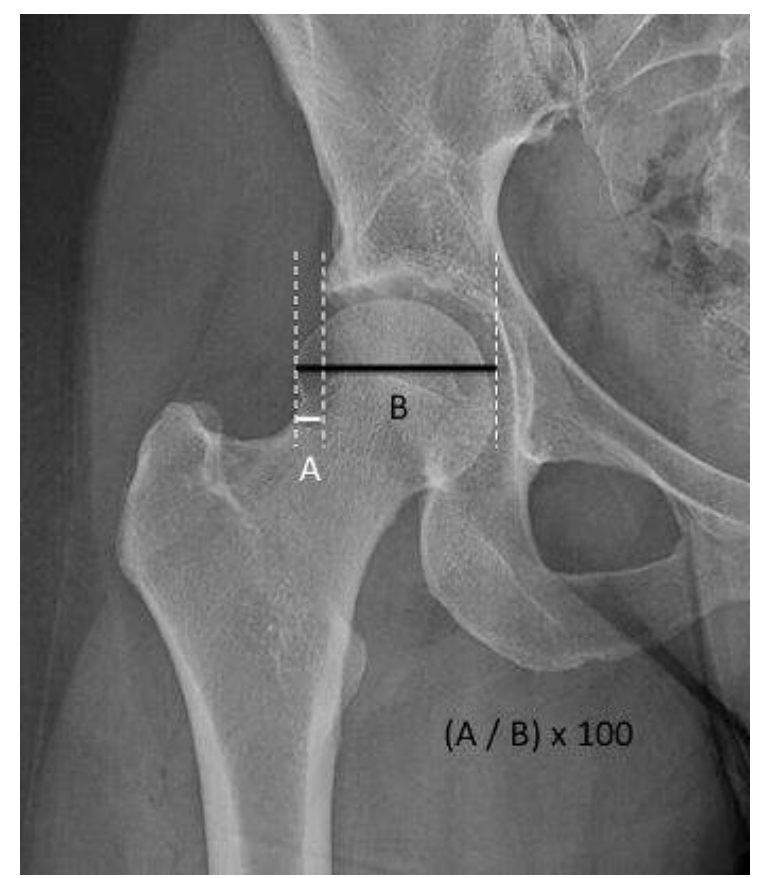

Figure 10. Acetabular coverage. Femoral head extrusion index: AP hip view. The percentage calculated by dividing the horizontal distance of the part of the femoral head that is lateral to the edge of acetabulum (A) by the total horizontal width of femoral head (B) and multiplied by 100 .

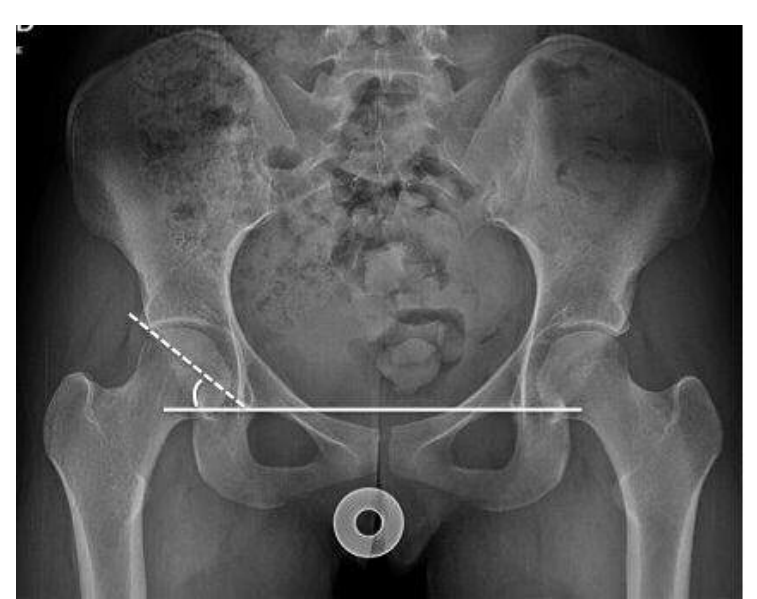

Figure 11. Acetabular inclination. Sharp's angle: AP pelvic view. Angle between a line horizontal to the inferior aspect of both pelvic teardrops, and a line from the inferior aspect of the teardrop passing through the most lateral point of the acetabular sourcil.

sphericity and evaluates femoral dysplasia ${ }^{5,12,14,15}$. It is defined as the angle between the femoral neck axis and a line connecting the center of the femoral head with the point where the sphericity of the head-neck contour ends. The normal value is still debated, however, there is sufficient agreement that an angle greater than $50^{\circ}$ is abnormal and more than $55^{\circ}$ is more specific for impingement (Figure $15 \mathrm{~b}$ ).

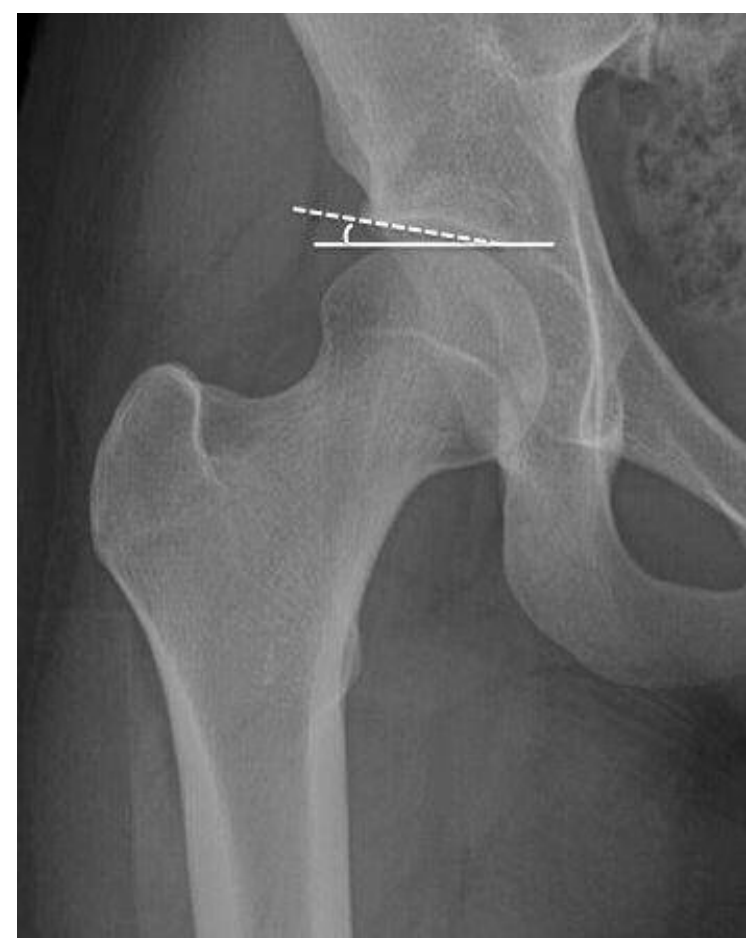

Figure 12. Acetabular inclination. Tönnis angle: AP hip view. Angle between the horizontal line, and a second line connecting the inferior and lateral aspects of the acetabular sourcil.

The pistol-grip deformity (Figure 16) is caused by an abnormal horizontal extension of the femoral epiphysis and characterized by a flattening of the concave surface of the head-neck junction ${ }^{5,16}$. Another radiographic sign of $\mathrm{FAl}$ are fibrocystic changes in the femoral offset. These are rounded radiolucent images of sclerotic rims generally in the anterosuperior quadrant of the femoral neck ${ }^{5,16}$ (Figure $17 \mathrm{a}, \mathrm{b}$ ).

The angle between the femoral neck and the shaft varies between $120^{\circ}$ and $140^{\circ}$. Coxa valga (Figure 18 a) is when this value is higher than $140^{\circ}$ and Coxa vara (Figure $18 \mathrm{~b}$ ) when the angle is less than $120^{\circ}$.

\section{Pathology of the hip}

The main indication for pelvic X-ray in adults is detection of osteoarthritis or conditions that precede it. Osteoarthritis is the most common joint disease ${ }^{17}$. It is characterized by the progressive degeneration of the articular cartilage ${ }^{18}$. Most imaging findings are late results of this process. Decreasing amplitude of the joint space, sclerosis, cysts and osteophytes are all signs of an advanced process, so its detection is a rather late diagnosis.

Currently it is believed that different etiologies can lead to a very similar process of degeneration in terminal phase. One such ethology relates to an articulation of "abnormal" morphology either by a deformity of the acetabulum and/or of the femur 

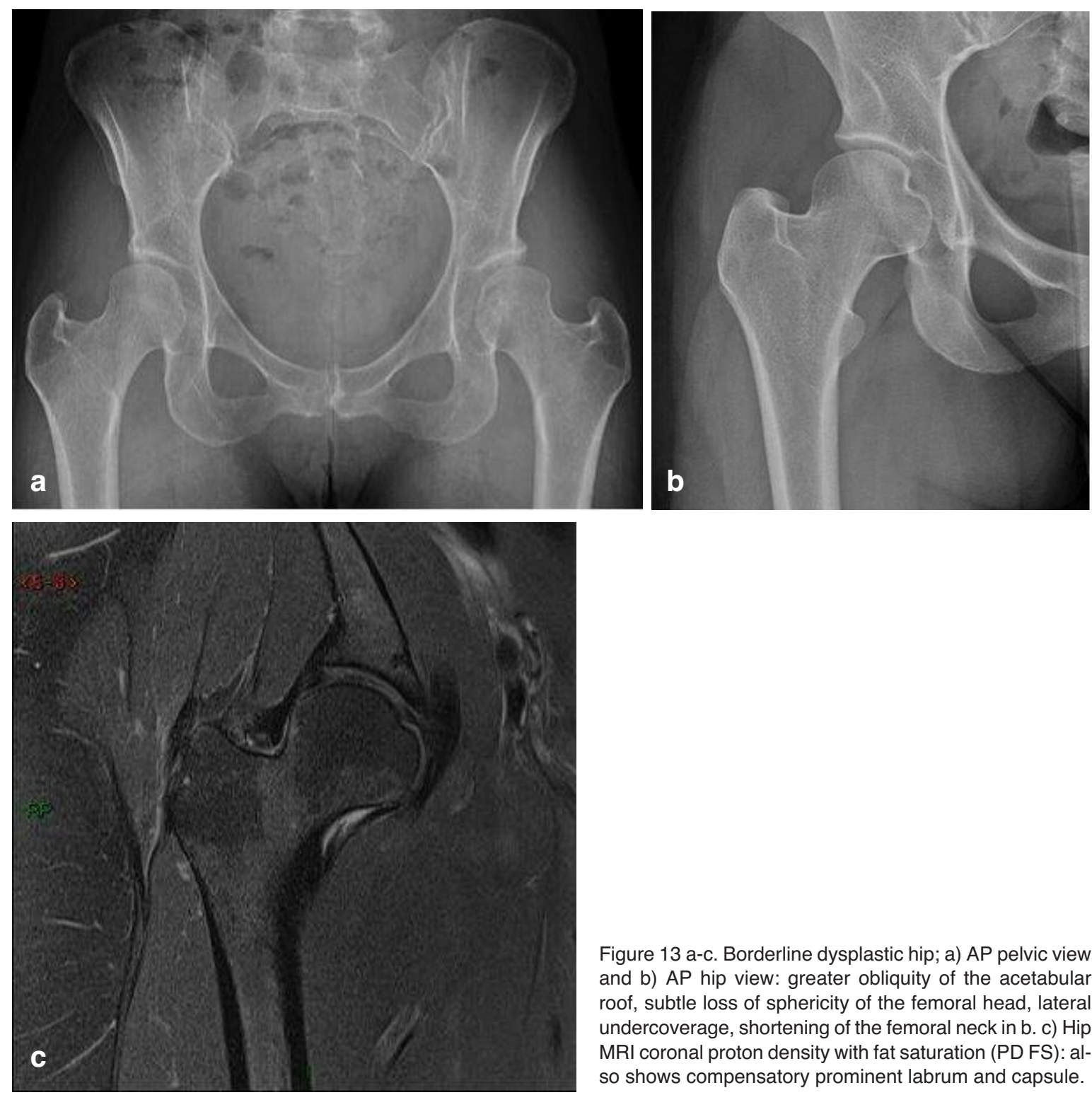

Figure 13 a-c. Borderline dysplastic hip; a) AP pelvic view and b) AP hip view: greater obliquity of the acetabular roof, subtle loss of sphericity of the femoral head, lateral undercoverage, shortening of the femoral neck in b. c) Hip MRI coronal proton density with fat saturation (PD FS): also shows compensatory prominent labrum and capsule.

(FAI). These bone abnormalities are highly predictive for the development of arthrosis of the hip, hence the high interest to detect them early and to offer better treatment options. Likewise, it is important to detect the "borderline" dysplastic hips early.

The cardinal signs in X-ray are: narrowing joint space as the result of chondral damage, subchondral sclerosis corresponding to the reparative bone reaction, osteophyte formation in low pressure areas of the joint which corresponds to a reparative attempt to maintain the stability of the joint and subchondral cysts, which etiology is debated, and are found both in the femoral head and the acetabulum.

MRI shows more directly all the findings described above and also adds valuable information that is not obtained with simple X-ray in relation to the state of the cartilage and the soft tissues: synovitis, joint effusion, intra-articular chondral/bone bodies, the state of the labrum, and the presence of bone edema in the subchondral regions. These signs, such as joint effusion and bone edema, are better correlated with the patient's clinical history, and provide additional information on the progress of the degenerative articular process (Figure 19 a-d).

\section{Ultrasound}

US is a valuable tool to answer specific questions regarding hip pathology. It is a widely available technique, relatively inexpensive that allows the dynamic and comparative evaluation of the tissues with the contralateral side.

The power doppler can add vascular information to 


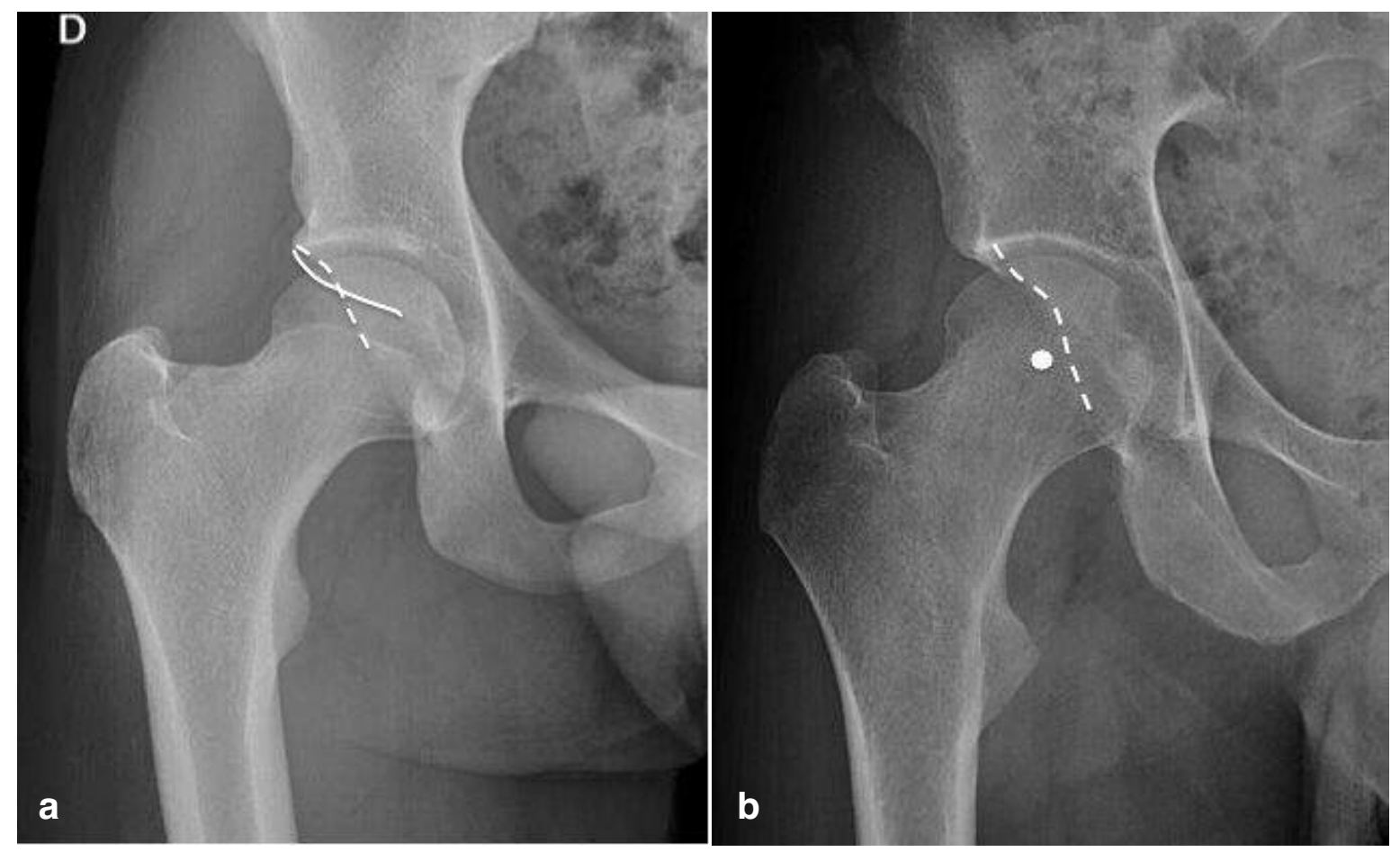

Figure 14 a, b. Acetabular retroversion; a) crossover sign, acetabular anterior wall (white line), acetabular posterior wall (dashed line); b) posterior wall sign, center of femoral head (dot) acetabular posterior wall (dashed line).
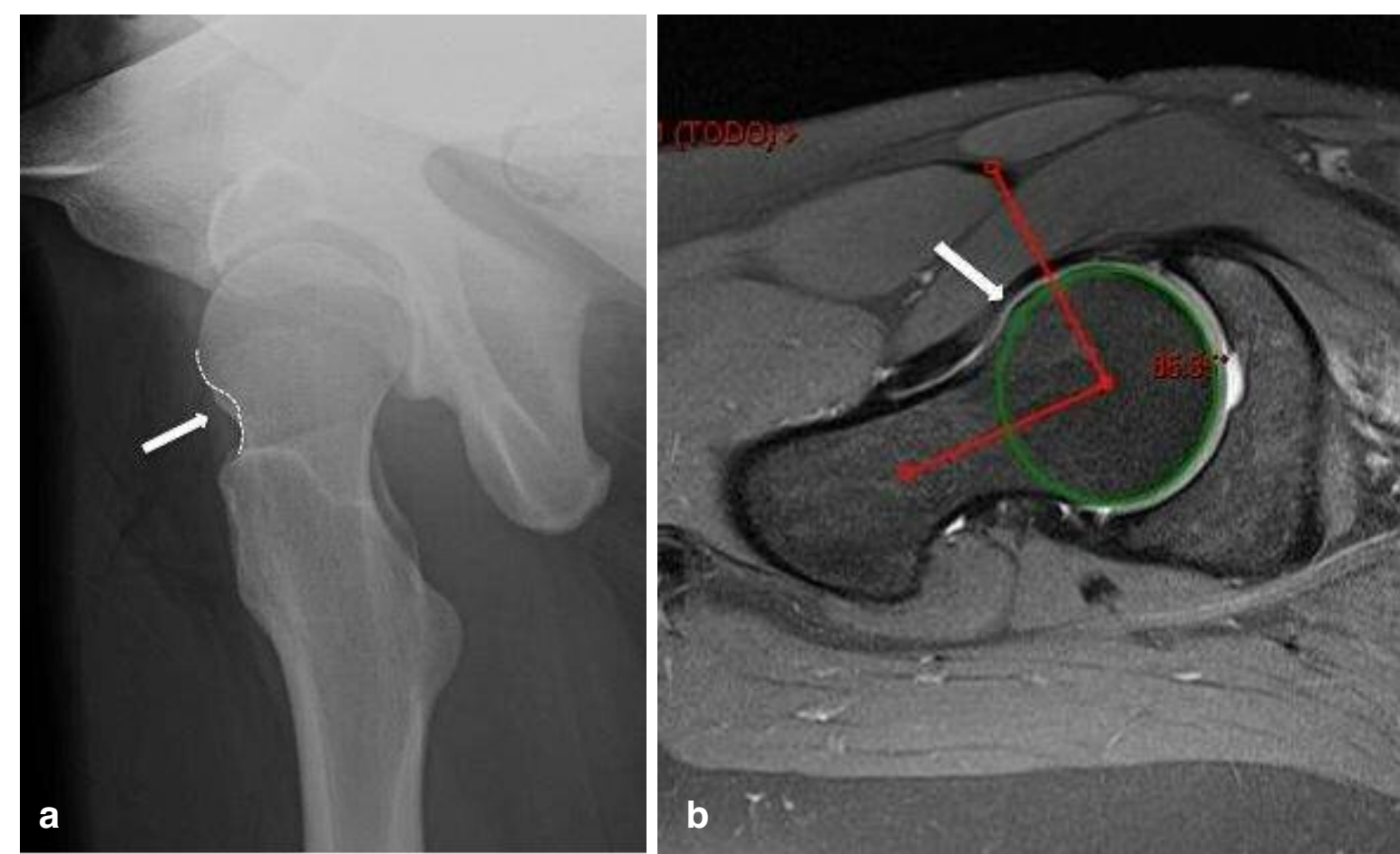

Figure 15 a, b. Loss of the anterior femoral offset; a) cross-table view, femoral offset (dashed line), bony prominence or bump (arrow); b) Hip MRI axial oblique PD FS. Alpha angle (red), bump (arrow).

the examination, for example by studying the synovium in rheumatoid arthritis, or vascularity of a soft tissue tumor.

It is especially useful for assessing the presence of 


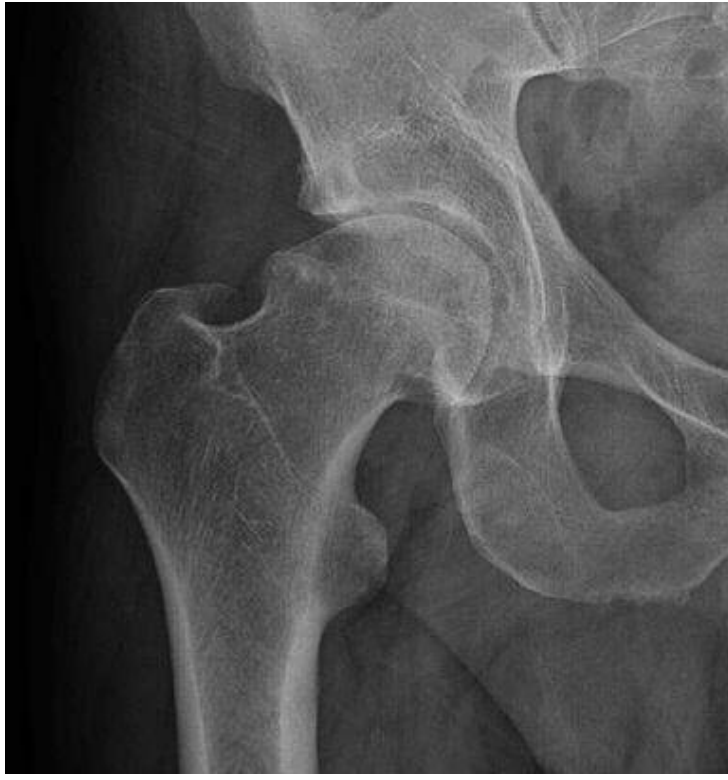

Figure 16. Pistol-grip deformity.

joint effusion (Figure 20 a) and assessment of bursae and tendons such as the psoas, rectus femoris, gluteus.

Because it is a dynamic technique, is useful for study of coxa saltans or snapping hip, medial and lateral ${ }^{19}$. Medial snapping hip is the most common, which consists in a snapping of the iliopsoas tendon over the iliopectineal eminence which can be directly observed with ultrasound. An audible snap or click can be heard when the hip is moved from flexion, abduction, and external rotation (frog leg position) to extension, adduction, and internal rotation. Moreover, is useful as a guide for diagnostic and/or therapeutic interventional procedures such as aspiration punctures and steroid injections ${ }^{20}$ (Figure 20 b).

The major limitations of US are: is an operatordependent technique and the learning curve is slow and takes a long time to become a fully trained and reliable operator.

\section{Computed tomography}

In recent years there have been extraordinary technical advances in computed tomography, making it a fast and widely available tool, which provides high spatial resolution and contrasted images, providing an excellent representation of the cortical, trabecular bone and joint anatomy ${ }^{20}$. Thus, CT is complementary to other diagnostic methods in many hip pathologies being particularly valuable in trauma and bone tumors (Figure $21 \mathrm{a}-\mathrm{c}$ ). Moreover, FAI patients who have a contraindication to undergoing MRI, CT arhrography could be an alternative to evaluate labrum and cartilage, as well as to characterize the acetabular and femoral bone alterations before surgery.
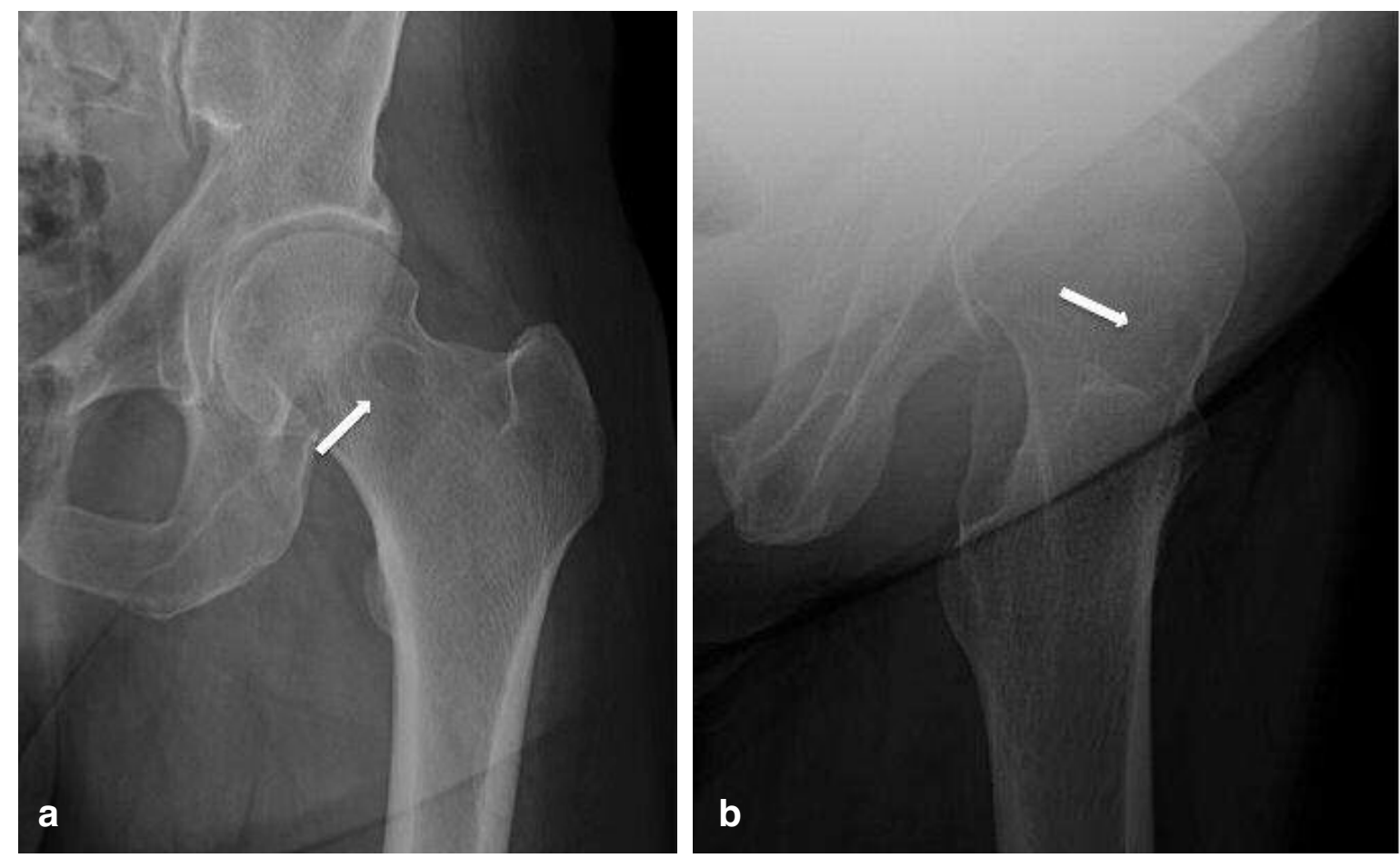

Figure 17 a, b. Fibrocystic changes in the femoral offset (arrow). 

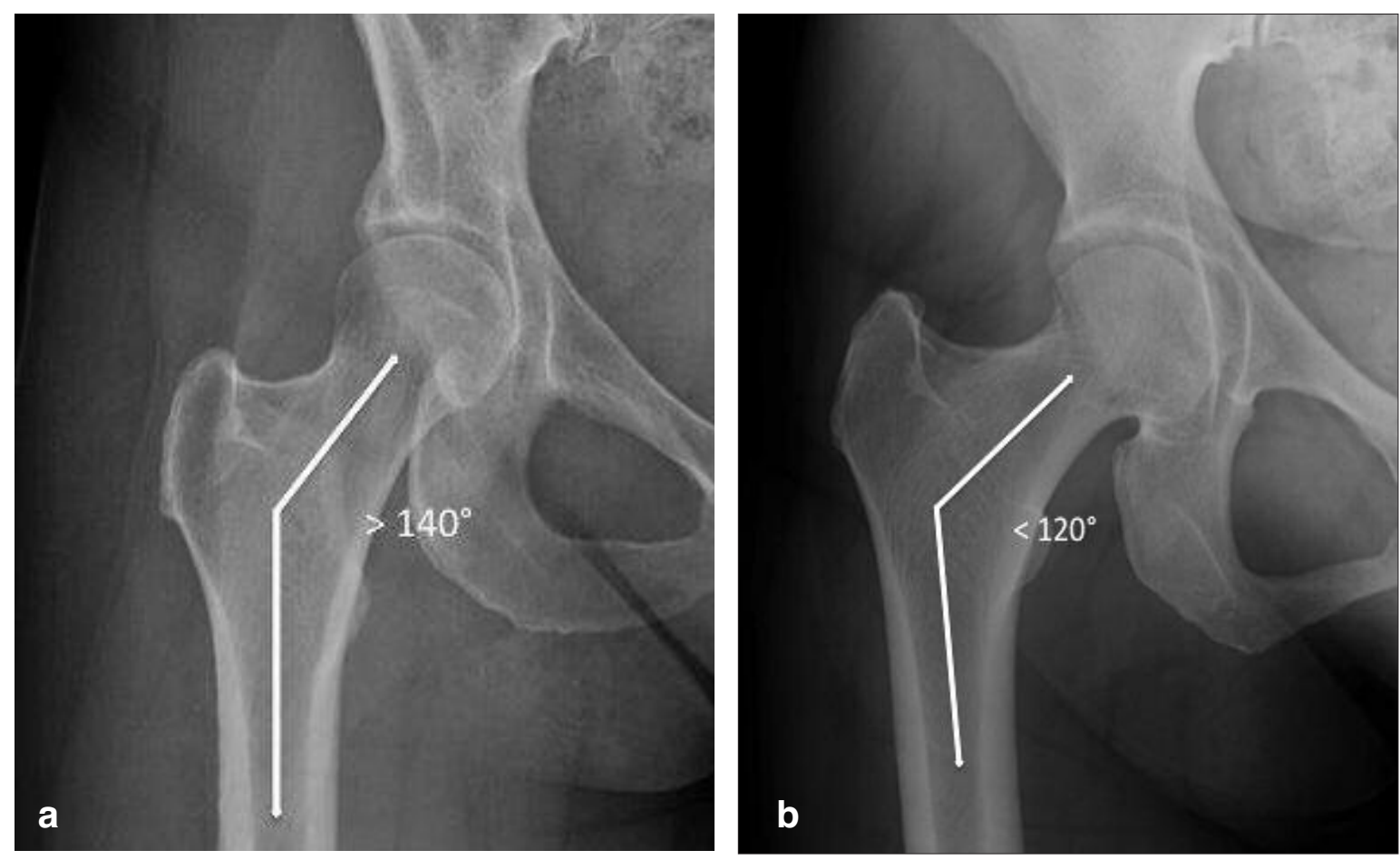

Figure 18 a, b. a) Coxa valga; b) Coxa vara.

\section{Magnetic resonance}

There are many hip pathologies that can be early detected with MRI due to its high resolution for soft tissues and high sensitivity representing the bone marrow $^{3}$. MRI is the examination of highest performance if osteonecrosis, transient hip osteoporosis, stress fractures, infiltrative bone marrow diseases, septic arthritis, osteomyelitis are suspected (Figure 22 a-c). It is also used to evaluate periarticular tendons and soft tissues, especially in the greater trochanter ${ }^{20}$.

The painful greater trochanter syndrome is characterized by pain and tenderness in this area ${ }^{21-24}$. Its diagnosis is based on medical history, physical examination and imaging studies. A great variety of pathological conditions can clinically simulate it, such as degenerative joint disease, $\mathrm{FAl}$, osteonecrosis, infection and conditions that can change the biomechanics of the hip such as knee osteoarthritis, iliotibial band friction syndrome or degenerative disease of the lumbar spine. Hence the need for the imaging studies.

The syndrome may be the result of trochanteric bursitis, gluteal tendinopathy, partial or complete tear of the gluteus medius and/or minimus tendons, coxa saltans or fascia lata tendinopathy.

US is useful evaluating pertrochanteric pathology, nevertheless, MRI also allows evaluation of the remaining structures of the hip.

MRI evaluates the state of the tendons, the presence of tears, bursae inflammation or bone marrow edema in the greater trochanter (Figure $23 \mathrm{a}, \mathrm{b}$ ).

In adults, hip MRI has a definite role in the assessment of osteoarthritis, especially in early onset or re- lated to $\mathrm{FAl}^{15}$ as it allows studying of the anatomical factors associated to impingement (already described above in X-ray evaluation), and the effect of this impingement on intraarticular structures such as the labrum and femoroacetabular cartilage ${ }^{25}$.

\section{MR arthrography}

It involves injection of contrast medium into the joint before obtaining images ${ }^{2}$. Arthrocentesis is often used to inject an anesthetic (for example lidocaine) and steroids. The Lidocaine test ${ }^{26}$ consists of intra articular injection of $100 \mathrm{mg}$ of lidocaine, which is verified under radioscopic vision with the use of a small quantity of iodinated contrast or under US. The test is positive when after the procedure the patient reports pain relief with maneuvers of hip flexion and rotations to assess impingement, which also contributes to the diagnosis (Figure 24).

MR arthrography has higher sensitivity and specificity than conventional MRI for the diagnosis of labral morphology and lesions, ligamentum teres, chondral lesions and intra-articular loose bodies ${ }^{5,15}$.

It is the best technique to study $\mathrm{FAI}^{13,14}$, its main indication, especially for evaluation of the acetabular labrum and the femoral and acetabular cartilage. If standard sequences are also included, additional information of the bone marrow is obtained.

The acetabular labrum is a triangular fibrocartilage firmly attached to the acetabular bone rim and the adjacent cartilage. It covers two thirds to three quarters of the circumference of the acetabulum and 

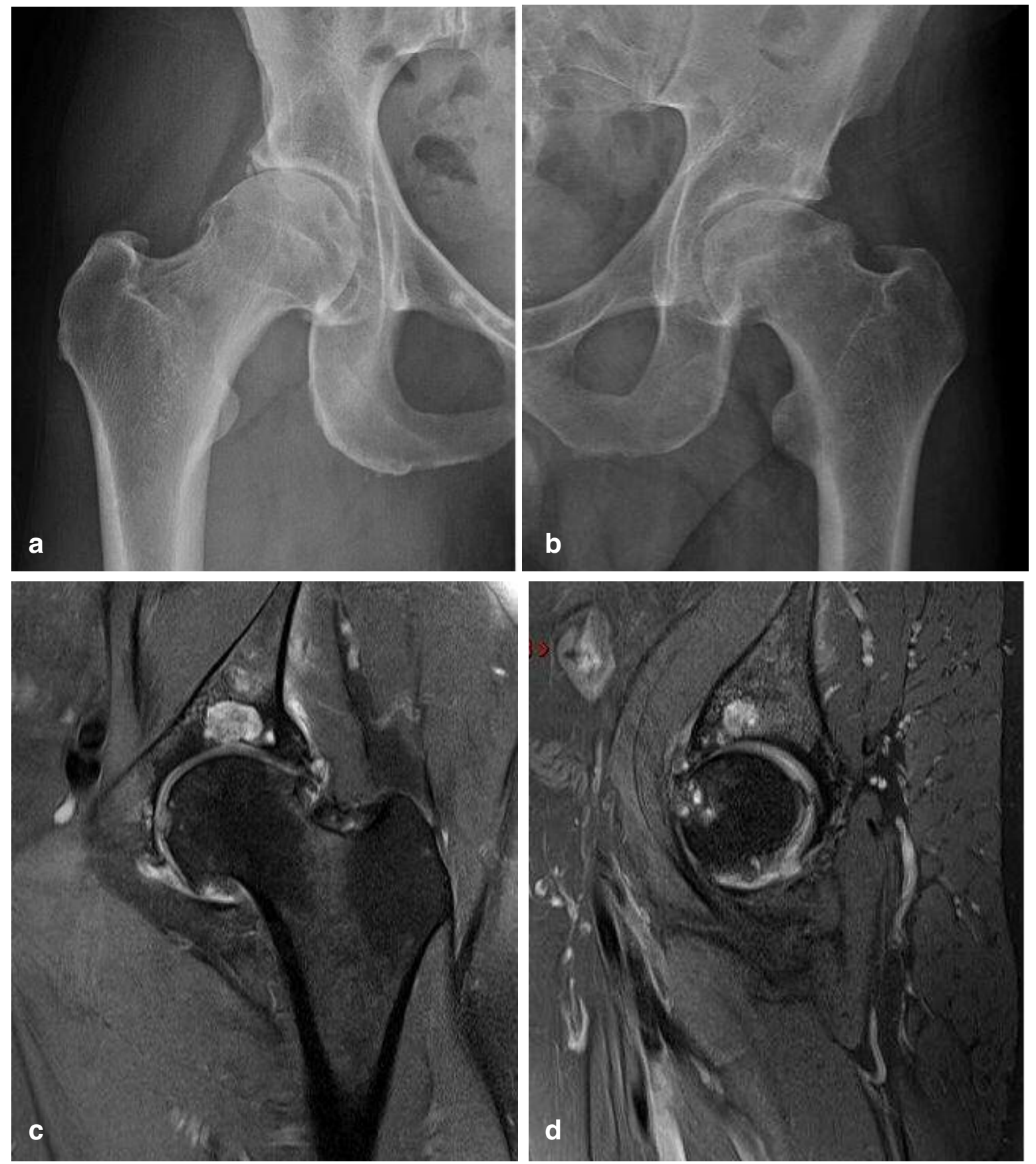

Figure 19 a-d. Osteoarthritis a, b) AP hip view; c,d) hip MRI coronal and sagittal PD FS of the same patient than b.

is absent in the lower anterior aspect. Since it's a fibrocartilage, its normal representation in MRI is low signal in all sequences. The most frequent finding in MR arthrography is a labral tear. The vast majority of the lesions occurs in the antero-superior aspect ${ }^{14}$. The diagnosis is established when there is a liquid interface, with the contrast medium between the labrum and its insertion into the acetabular rim or cartilage. The accumulation of contrast outside this labral insertion or the presence of a perilabral cyst increases diagnostic accuracy ${ }^{11}$ (Figure $25 \mathrm{a}, \mathrm{b}$ ).
Chondral lesions such as ulcers, fissures and delamination can also be detected ${ }^{18,27,28}$, being less accurate for partial thickness lesions and nondisplaced flaps or fissures (Figure 26).

For CAM type impingement, which is caused by the entrapment of an abnormal non-spherical femoral head in the acetabulum especially in maximum flexion, a triad of signs in MR arthrography have been described: abnormal alpha angle, antero-superior chondral lesion, antero-superior labral tearing ${ }^{5,27}$ 

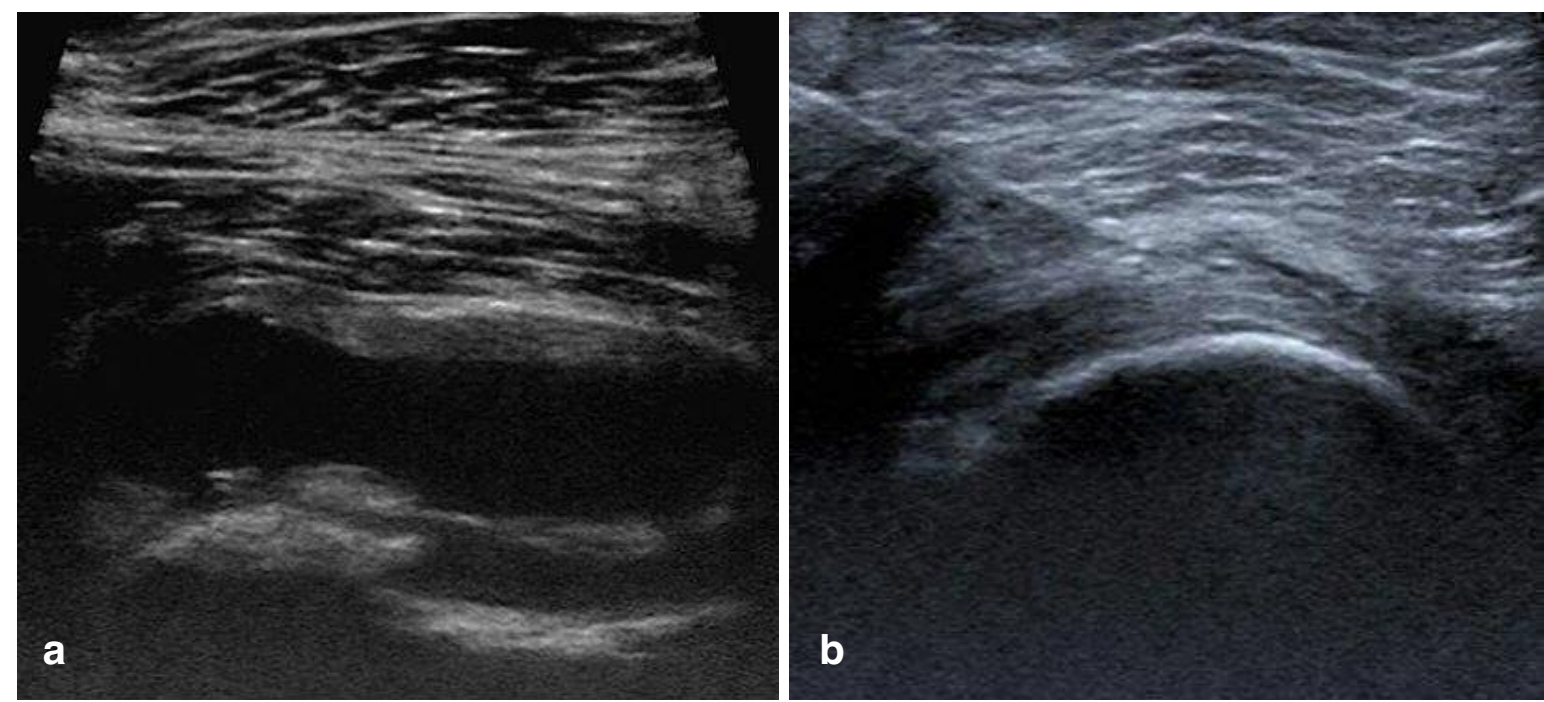

Figure 20 a, b. Hip ultrasound; a) joint effusion and sinovitis in anterior femoro acetabular articular recess; b) needle injection under ultrasound guidance in anterior femoro acetabular articular recess.
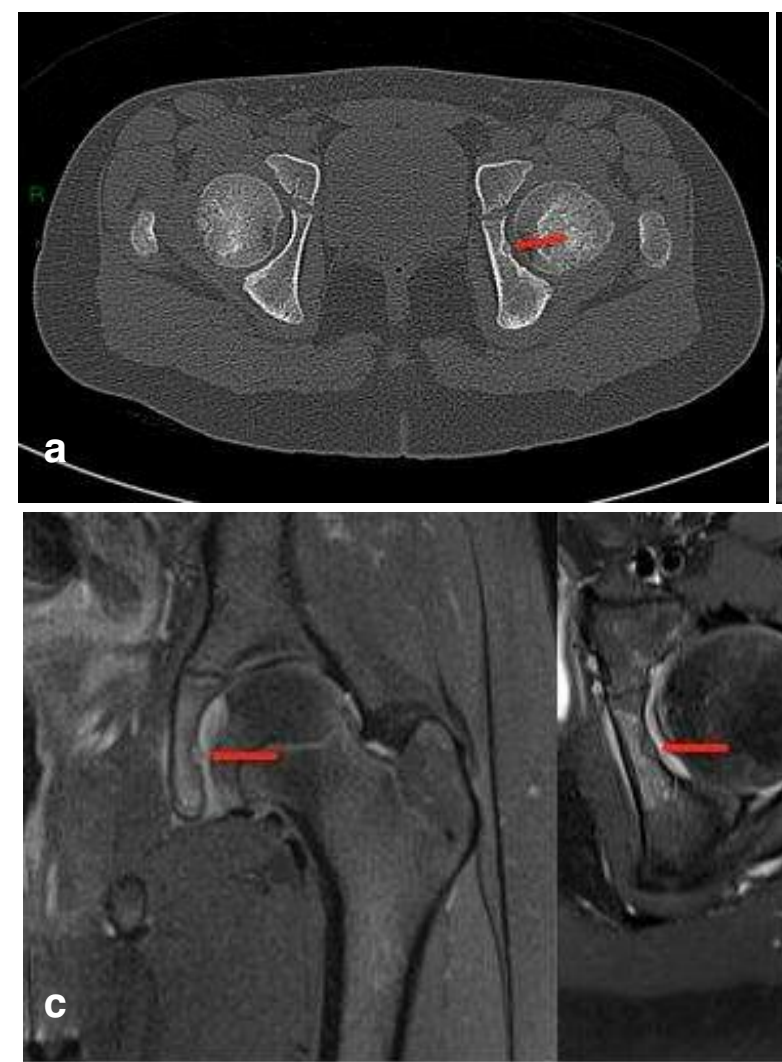

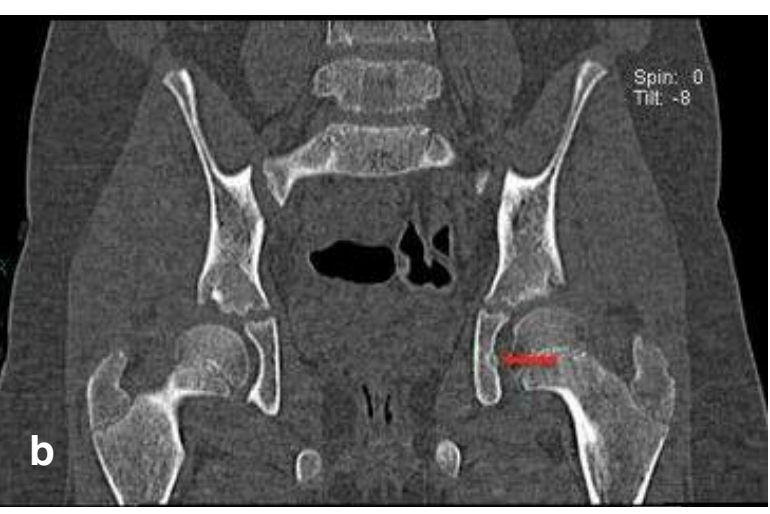

Figure 21 a-c. Osteoid osteoma in the acetabular floor (red arrow) in a 9-year-old girl with normal radiographs and left hip pain; a, b) pelvis CT axial and coronal views show the small bony lesion; c) hip MRI coronal PD FS and axial T1 FS with intravenous gadolinium, also show marrow edema and hyperemia, synovitis and periostitis.
For pincer type impingement, which is caused by acetabular over coverage, the chondral lesions occur frequently in the posterior aspect of the acetabulum because of the "contrecoup" type lesion. Labral tear and degeneration is more common in the anterosuperior margin ${ }^{27}$.

\section{Cartilage maps}

These are MRI techniques under development, that do not study the morphology of the lesion. These provide quantitative information on the composition of the cartilage, especially useful in the evaluation of its 

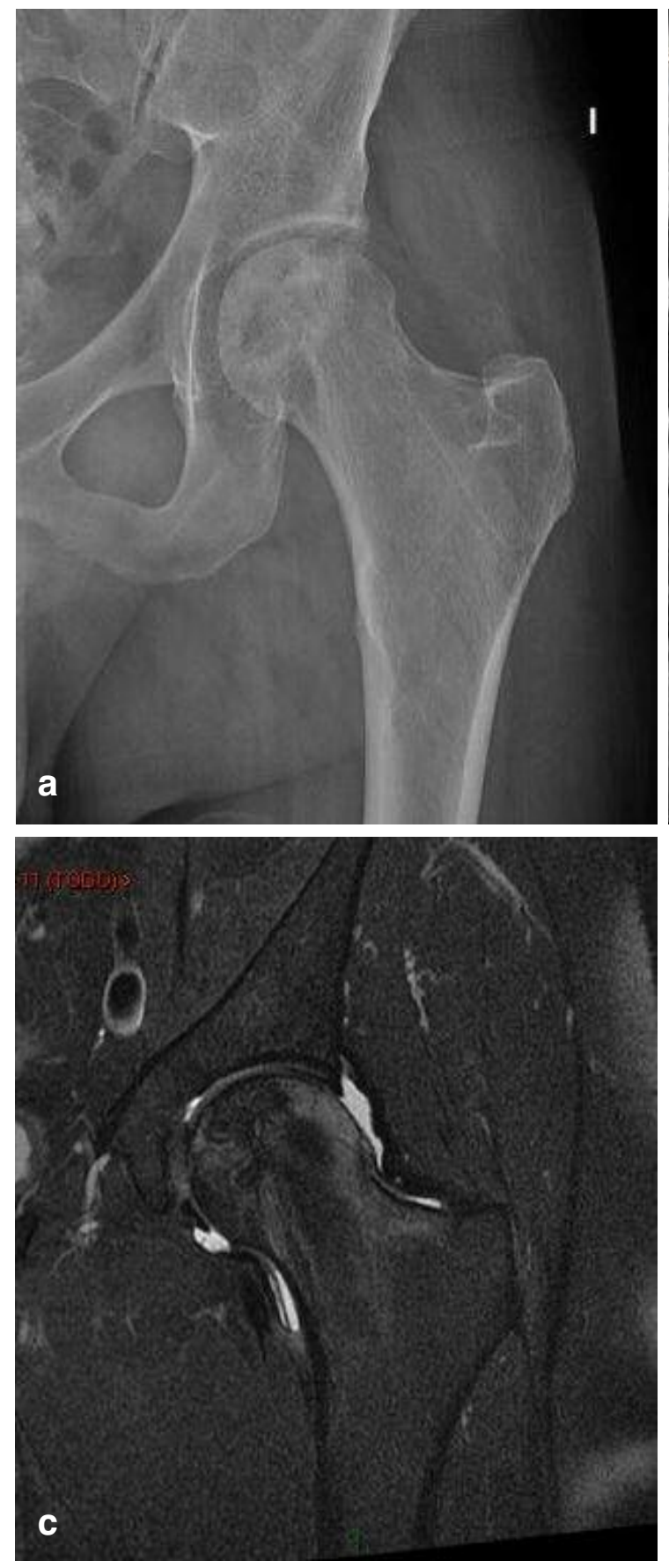

status before the existence of macroscopic focal lesions, detectable with conventional techniques. We will mention only two of them in current medical use. In the hip, T1 maps have been used to study the cartilage in T1 sequences after intravenous injection of paramagnetic contrast (gadolinium). The technique is called dGEMRIC: (delayed gadolinium-enhanced magnetic resonance imaging of cartilage $)^{29,30}$.

The glycosaminoglycans (GAGs) which form part of the cartilage have negative charges on the carboxylate and sulphate groups. It is known that with the

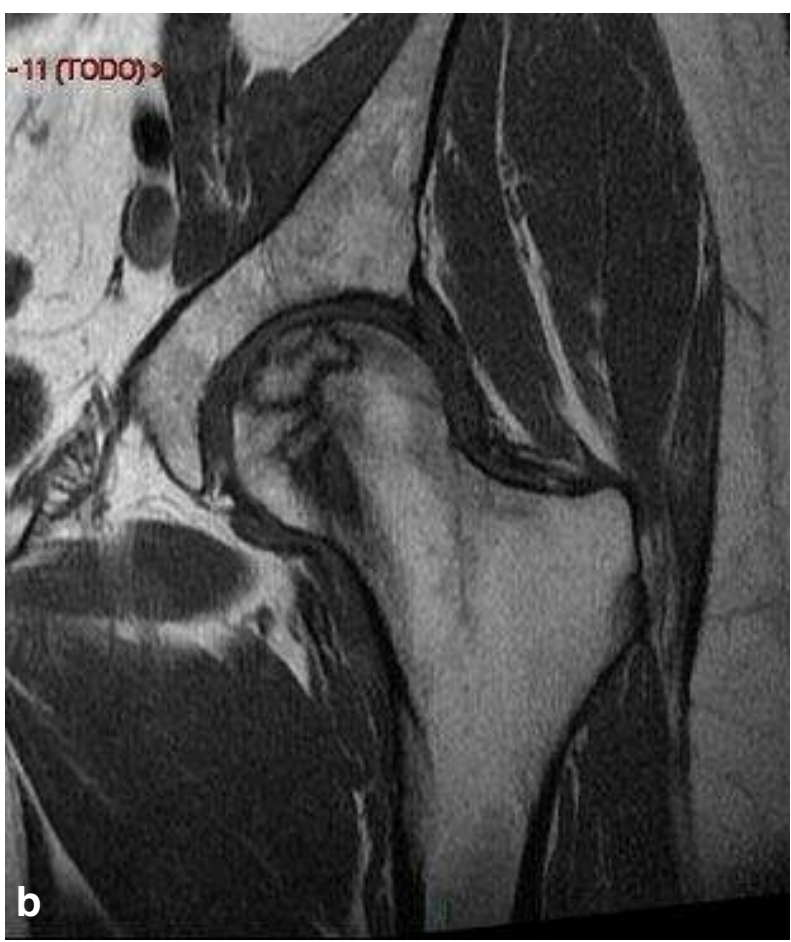

Figure 22 a-c. Osteonecrosis of the femoral head; a) hip AP view; b) hip MRI coronal T1; c) hip MRI coronal PD FS.

articular cartilage aging and degenerative processes, the amount of proteoglycans decreases.

If there is normal amount of GAGs possessing charge (-) and gadolinium also has charge (-), it will be repelled and will not penetrate by diffusion into the cartilage.

When the amount of GAGs is decreased it allows contrast to penetrate and impregnate the cartilage in affected areas. Gadolinium accumulates where there are less GAGs. This increased uptake can be represented in a color map $^{29}$ (Figure 27 ). 

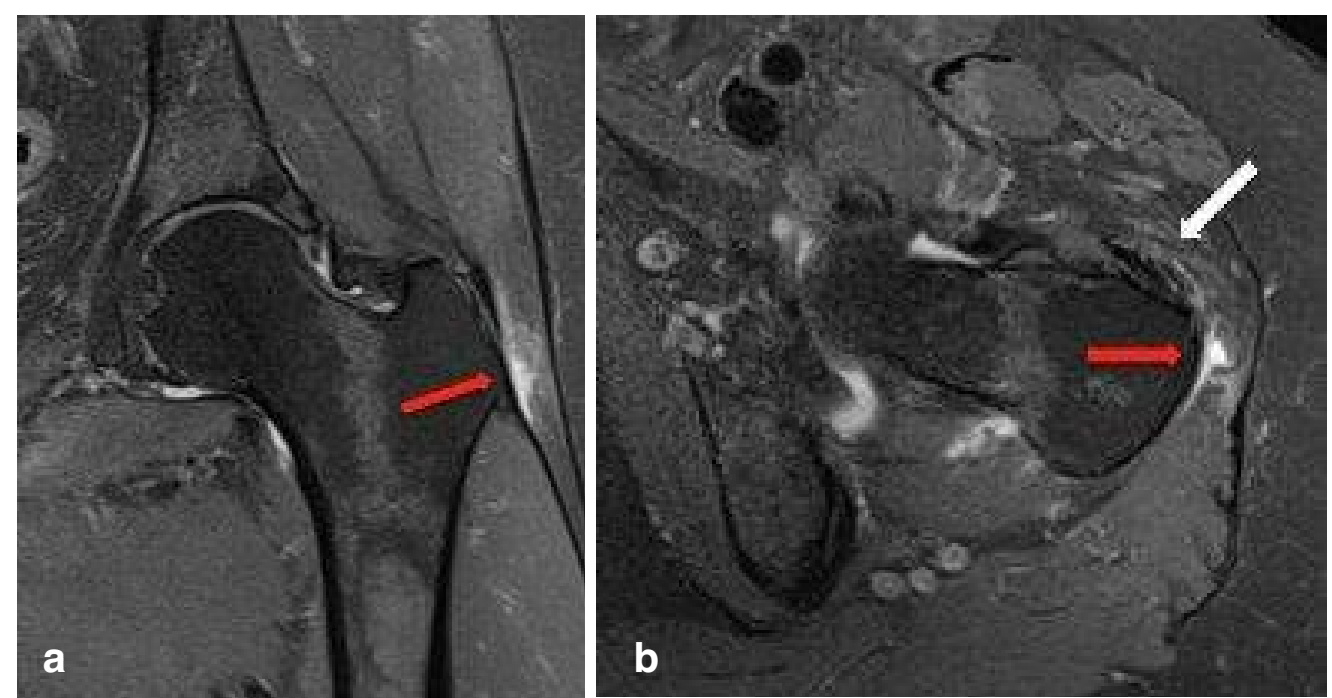

Figure 23 a, b. Painful greater trochanter syndrome; a, b) hip MRI coronal and axial PD FS, bursitis (red arrow), gluteus mimimus tendinopathy (white arrow).

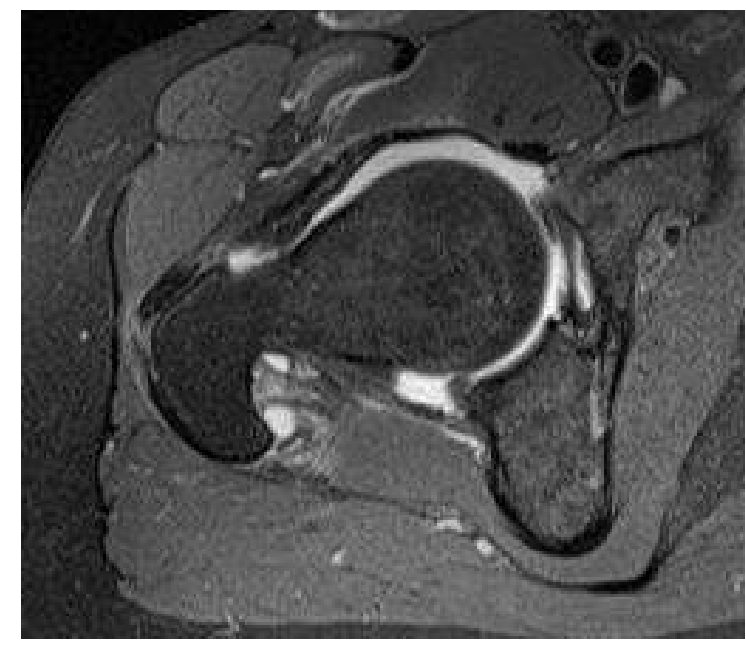

Figure 24. MR arthrography of the hip. Axial PD FS with intraarticular saline solution as contrast medium.

The T2 map is used to detect water. With this technique it is possible to measure the T2 relaxation time of the cartilage, which in normal cartilage are lower in the deeper layers when collagen fiber framework is more compact and there is less amount of water. T2 relaxation times increase towards the outermost portions of cartilage. This method is essentially based on that the degenerative alterations cause disruption of the collagen matrix, which becomes looser allowing higher content of $\mathrm{H}_{2} \mathrm{O}$ protons which are also freer, which produces an increase of values of T2 relaxation over the normal levels.

With a suitable software, it is possible to measure T2 relaxation time in milliseconds in the area of interest, which enables to quantified the changes objectively. It is shown using a color map ${ }^{30}$ (Figure 28).
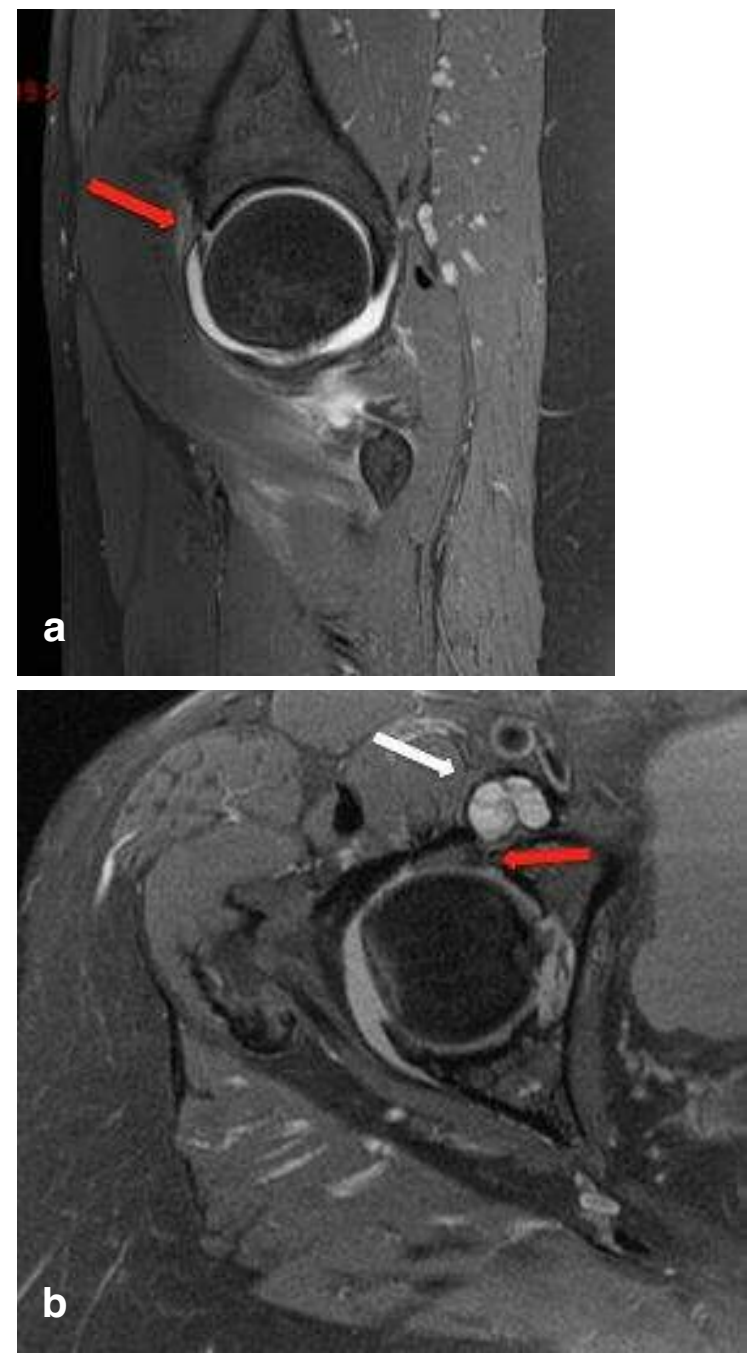

Figure 25 a, b. MR arthrography of the hip; a) sagittal PD FS, labral tear (red arrow); b) axial PD FS, labral tear (red arrow), perilabral cyst (white arrow). 


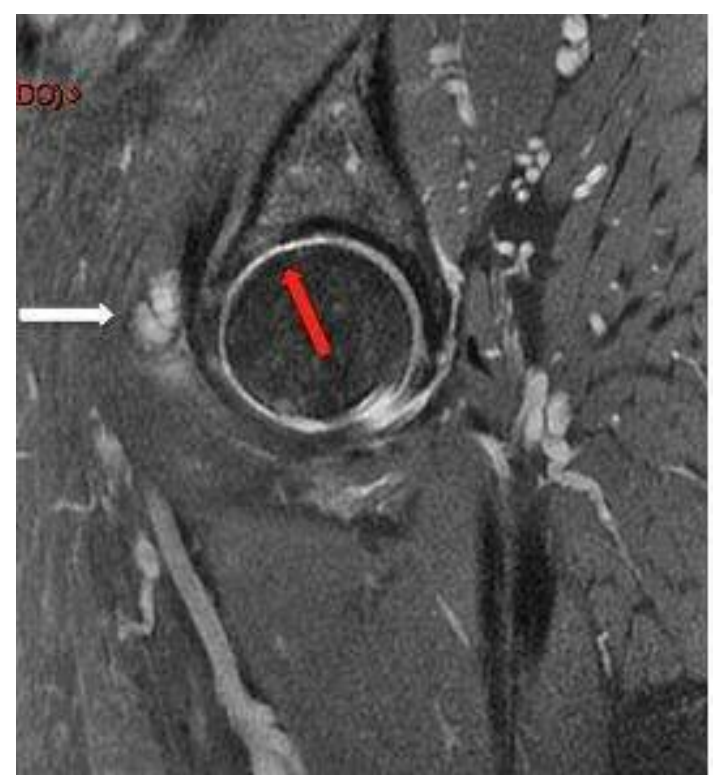

Figure 26. MR arthrography of the hip. Sagittal PD FS, full thickness cartilage lesion filled with fluid (red arrow), perilabral cyst (white arrow).

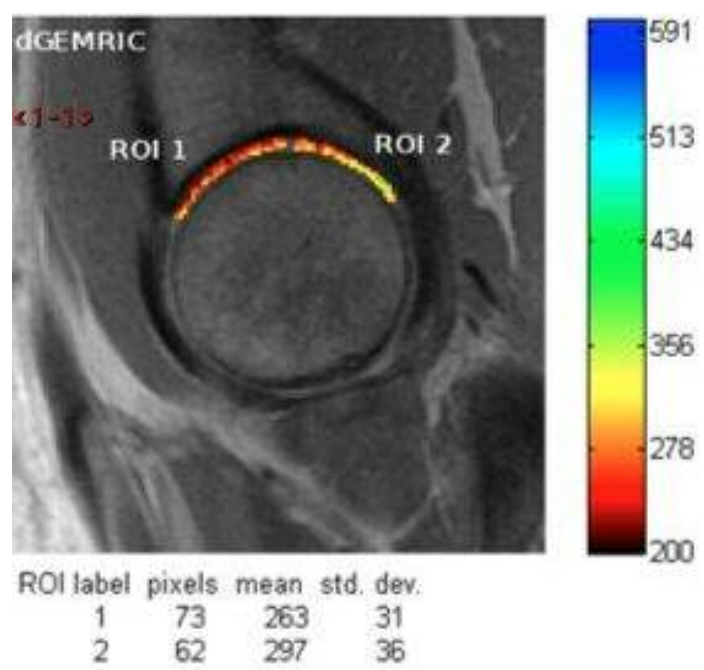

Figure 27. dGEMRIC T1 map of femoroacetabular cartilage.

\section{Conclusion}

The imaging study of the hip should always consider a simple X-ray which provides meaningful information but often not enough to make treatment decisions. Other imaging techniques provide relevant information that cannot be determined with simple X-ray. US is helpful in assessing joint effusion and/or synovitis. It also serves as a guide for therapeutic or diagnostic punctures. CT is an excellent tool to study the bone, especially in anatomically complex areas. MRI provides the assessment of bone marrow and soft tissues. MR arthrography has higher sensitivity and specificity for the diagnosis of labral and

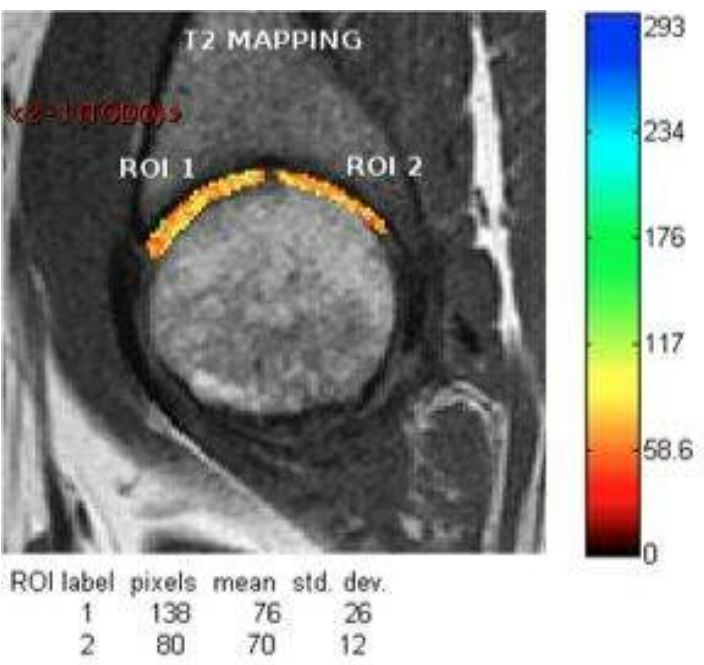

Figure 28. T2 map of femoroacetabular cartilage.

chondral lesions. The great future challenge is to improve detection techniques for chondral damage before they are macroscopically visible.

\section{References}

1. Clohisy JC-H. A systematic approach to the plain radiographic evaluation of the young adult hip. The Journal Bone and Joint Surgery Am. 2008;90:47-66.

2. Karrasch C, Lynch S. Practical Approach to Hip Pain. Medical Clinics of North America. 2014;98:737-754.

3. Karantanas A. Imaging of the Hip. Journal Rentgenologiya i Radiologya. 2012;51:220.

4. Padulo J, Oliva F, Frizziero A, Maffulli N. Muscles, Ligaments and Tendons Journal. Basic principles and recommendations in clinical and field science research: 2016 Update. MLTJ. 2016;6(1):1-5.

5. Dimmick S, Stevens KJ, Brazier D, Anderson SE. Femoroacetabular Impingement. Radiologic Clinics. 2013;51:337-352.

6. Tannast M, Siebenrock KA, Anderson SE. Femoroacetabular Impingement: Radiographic Diagnosis-What the Radiologist Should Know. American Journal of Roentgenology. 2007; 188:1540-1552.

7. Manaster BJ. Adult Chronic Hip Pain: Radiographic Evaluation. Radiographics. 2000;20:3-25.

8. Ruiz Santiago F, Santiago Chinchilla A, Asnari A, et al. Imaging of Hip Pain: from Radiography to Cross-Sectional Imaging Techniques. Radiology Research and Practice. 2016;15.

9. Gala L, Clohisy JC, Beaulé PE. Hip Dysplasia in the young Adult. J Bone Joint Surg Am. 2016;98:63-73.

10. Nepple JJ, Clohisy JC. The Dysplastic and Unstable Hip: a Responsible Balance of Arthroscopic and Open Approaches. Sports Medicine and Arthroscopic Review. 2015;23:180-186.

11. Paliobeis CP, Villar RN. The prevalence of dysplasia in femoroacetabular impingement. Hip Int. 2011;21:141-145.

12. Bredella MA, Ulbrich EJ, Stoller DW, Anderson SE. Femoroacetabular Impingement. Magnetic Resonance Imaging Clinics. 2013;21:45-64.

13. Kassarjian A, Belzile E. Femoroacetabular Impingement: Presentation, Diagnosis, and Management. Seminars in Musculoskeletal Radiology. 2008;12:136-145.

14. Fadul DA, Carrino J A. Imaging of Femoroacetabular Impingement. J Bone Joint Surg Am. 2009;91:138-143. 
15. Pulido L, Parvizi J. Femoroacetabular Impingement. Seminars in Musculoskeletal Radiology. 2007;11:66-72.

16. Kim JA, Park JS, Jin W, Ryu K. Hernitation pit in the femoral neck. A radiographic indicator of femoroacetabular impingement. Skeletal Radiology. 2011;40:167-172.

17. Siebelt M, Agricola R, Weinans $\mathrm{H}$, Kim YJ. The role of Imaging in early OA. (OARSI, Ed.) Osteoarthritis and Cartilage. 2014;22:1470-1480.

18. Anderson LA, Peters CL, Park BB, Stoddard GJ, Erickson JA, Crim JR. Acetabular Cartilage Delamination in Femoroacetabular Impingement. J Bone Joint Surg Am. 2009;91:305-313.

19. Deslandes M, Guillin R, Cardinal E, Hobden R, Bureau NJ. The Snapping lliopsoas Tendon: New Mechanism Using Dynamic Sonography. AJR Am J Roentgenol. 2008;190:576581.

20. Morrison WB, Zoga AC. Imaging of the Hip. Seminars in Arthroplasty. 2005;16:10-26.

21. Kingzett-Taylor A, Tirman PF, Feller J, McGann W, et al. Tendinosis and Tears of Gluteus Medius and Minimus Muscles as a Cause of Hip Pain: MR Imaging Findings. AJR Am J Roentgenol. 1999;173:1123-1126.

22. Klontzas ME, Karantanas AH. Greater trochanter pain syndrome: A descriptive MR imagining study. Eur J Radiol. 2014;83:1850-1855.

23. Redmond JM, Chen AW, Domb BG. Greater Trochanteric
Pain Syndrome. J Am Acad Orthop Surg. 2016;24:231-240.

24. Parodi D. Peritrochanteric diseases surgical management. International Surgery Journal. 2016;3:431-433.

25. Diaz-Ledesma C, Casaccia M, Parvizi J. Report of magnetic resonance images of the hip in patiens with femoroacetabular impingement: is useful information provided to the orthopedic surgeon? Skeletal Radiology. 2013;42:335-340.

26. Mardones R, Barrientos V, Nemtala F, Tomic A, Salineros M. Pinzamiento femoroacetabular: Conceptos básicos en una nueva causa de dolor inguinal. Revista Médica de Chile. 2010;138:102-108.

27. Kassarjian A. Hip Arthrography and Femoroacetabular Impingement. Seminars in Muscloskeletal Radiology. 2006;10: 208-219.

28. Pfirrmann CW, Duc SR, Zanetti M, Dora C, Holder J. MR Arthrography of Acetabular Cartilage Delamination in Femoroacetabular Cam Impingement. Radiology. 2008;249:236-241.

29. Sur S, Mamisch T, Hughes T, Kim YJ. High Resolition Fast T1 Mapping Technique for dGEMRIC. Journal of Magnetic Resonance Imaging. 2009;30:869-900.

30. Sutter R, Zanetti M, Pfirmann CW. New Developments in Hip Imaging. Radiology. 2012;264:251-667.

31. Hesper T, Hosalkar H, Bittersohl D, et al. T2* mapping for articular cartilage assessment: principles, current applications, and future prospects. Skeletal Radiology. 2014;43:1429-1445. 